\title{
The Research of Cultural and Creative Product Design Based on the Zen Buddhism Culture
}

\author{
Ming $\operatorname{Lan}^{1,2}$ \\ ${ }^{1}$ Art and Design College \\ University of South China \\ HengYang, China \\ ${ }^{2}$ Department of Industrial Design, \\ Pukyong National University \\ Busan, Korea
}

\author{
Jang Chung Gun* \\ Department of Industrial Design, \\ Pukyong National University \\ Busan, Korea
}

\begin{abstract}
Facing the creative and connotative value of cultural product market, the Zen culture is undoubtedly the inspiration for the research and development of cultural and creative products. This paper attempts to dig deep value from the perspective of Zen Buddhism culture, analyzes its cultural connotation, aesthetic value, and philosophical implication, proposes a specific design method for creative transformation, and explores how to design a culturally innovative product with market value. Through the continuous digging of the cultural symbolic elements of the Zen culture and the cross -boundary design method used to find the association point, and then design the creative products with the creativity as the core and the life zen culture as the characteristic. Through the design practice, the design method is verified, which provides guidance for the innovative design of cultural and creative products.
\end{abstract}

Keywords-Zen Buddhism culture; Life Zen; cultural and creative product; design; cross-border fusion

\section{INTRODUCTION}

Compared with the richness of Zen Buddhism culture resources, the innovation of its cultural and creative product is facing difficulties; almost all of them are decorations and ornaments for praying for peace and safety. In the past two years, our cultural and creative products have achieved good market response with deep value mining, $R \& D$ and design, and especially the museum's cultural and creative products have been welcomed by the public. In 2015, the sales volume of the Palace Museum cultural and creative products reached nearly RMB 1 billion. In the cultural and creative products market that has increasingly gained credibility through cultural, story, and practicality, the designer market sensitivity of the products based on Buddhism culture is poor, and the solidity of thinking has led to low product visibility and reputation. This paper tries to dig deep value from the perspective of Zen Buddhism culture to explore the way to carry out creative transformation and design a cultural and creative product with market value starting from the analysis of its cultural resources.

\section{DEVELOP CULTURAL AND CREATIVE PRODUCTS BASED ON ZEN BUDDHISM CULTURE}

There are mainly eight schools of Buddhism in the Han Dynasty, namely Cittamatra, School of the Three Treatises,
Tiantai Sect, Huayan Sect, Zen, Pure Land Sect, the School of Vinaya and Tantra. However, due to various problems that have arisen during the development of Buddhism and four Buddhist difficulties, many sects have been severely weakened. Only Zen and Pure Land Sect didn't get influenced a lot because they did not write texts. The Pure Land Sect specializes in the reforestation of the Amitabha Pure Land and hopes to escape from the reality of the world of Sahara, and to surpass the pure land world. Different from the practice of Buddhism in Pure Land Sect, Zen emphasizes epiphany, and believes that the Buddhist scriptures are only a tool for enlightening people's understanding. The key lies in the consciousness of the person himself and his insight into the mind. Zen reconnects the "sacred Buddha character to people's real souls, realizes self-liberation by relying on self-confidence and self-awareness, embeds the seemingly profound Zen philosophy in daily life, and enables Buddhism that originally claimed to be passively 'born' to face life with the color of 'entering the world"' [1]. Zen Buddhism has thus become the most distinctive and far-reaching sect in Chinese Buddhism.

\section{A. Create cultural connotation of cultural and creative products with Zen Buddhism culture as the core}

The founder of Zen is Bodhidharma, and then he passed the abbot from Dazu Huike, Jianzhi Sengcan and Dayi Daoxin to Fifth Zen Patriarch Hongren. "Bodhi is fundamentally without any tree; the bright mirror is also not a stand. Fundamentally there is not a single thing - where could any dust be attracted?" was the Tang Dynasty monk Hui-neng's awakening to truth, embodying his clear-minded insight and the realization of the Buddha. With this Buddhist hymn, Hui-neng became the Sixth Patriarch of Zen and set off a Buddhist revolutionary movement to complete the sinicization, secularization, and popularization of Buddhism, making the Zen Buddhism culture an important part of Chinese traditional culture. Zen Buddhism "differs from the traditional practice of Buddhism that used to study verses, worship Buddha statues, and complex rituals in the past."[2] It surpassed the religion with the transcendental and penetrating attitude, went back to the return of the self, went to the road of human culture, became the link of the Confucianism, Buddhism and Taoism, formed the Zen thought system with Chinese characteristics, and established the mainstream position of Zen in the Buddhist circles. The 
development of Zen Buddhism culture has not been abandoned but integrated into modern life. Its recognition of Japan, South Korea, Europe and the United States is very high. The direct and unique thought and open character of Zen Buddhism culture are undoubtedly an important human resource today.

\section{B. Promote the artistic value of cultural and creative products by taking Zen aesthetics as enlightenment}

Zen Buddhism merged with Zhuangzi's aesthetics of the pre-Qin period and Wei and Jin's metaphysical aesthetics, and eventually developed Zen aesthetics. Many literary theorists and estheticians since the Tang Dynasty introduced the "epiphany" of Zen into literary theories and aesthetic theories, making Chinese aesthetics full of natural, quiet and true life, and the philosophy of life and aesthetic taste. The enlightenment of the aesthetic nature of Zen natural view on the design of cultural and creative products can be divided into two levels. The first level is the respect of nature, representing as the use of natural materials, reduction of artificial traces and the approximation to the true nature of life in an uncared and natural manner. For example, the utensils, which are not so shiny on the surface and have become dark with the passage of time, show the natural traces of the passing of time, and realize the Zen in the illiquid life. The second level is natural mind. Nature is the means of realization. For cultural and creative product design, naturalism of this level is manifested by seeking inspiration from the biological and ecological phenomena of the natural world, such as a flower, a tree, a tree, etc., to create textures with natural surface roughness and fine looseness, become the nature that transcends time and space and achieve the purpose of recognizing the essence of the mind and improving the spiritual realm. See Figure 1.

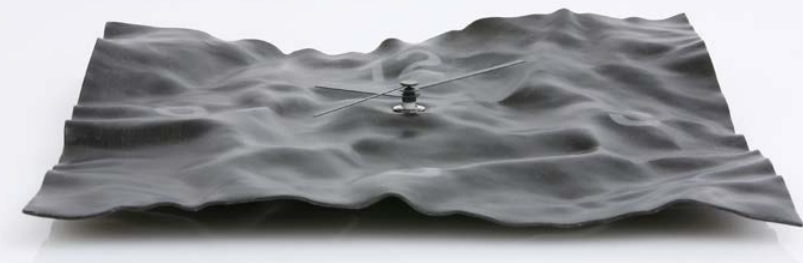

Fig. 1. Design of Zen clock

\section{Combine the philosophy and wisdom of "Life Zen" with contemporary spiritual needs}

The development of Zen meditation has played a prominent role in the development of contemporary Buddhism in China. In the development of various Zen philosophies, life meditation has become the most eye-catching one. In Zen Buddhism, Baizhang Huaihai and others are examples of combining Buddhist practice with daily life and putting it into practice. It emphasizes the understanding of Buddhism in the general life, and thus enters the supreme realm of the Zen Buddhism. It is nothing but a good way to transport water and transport wood. There is a normal life of zen.

Zen on the one hand inherits the aesthetic implication of Zen aesthetics, which is "enlightenment, emptiness and cleanness". On the other hand, it is a happy Zen with the characteristic of optimism and vitality. The Zen Buddhism of Chinese Buddhism, in addition to inheriting the essence of Buddhism, has a lot of Zhuang Zhou's shadow in the philosophy of life but is uniquely innovative. Zhuang Zhou's ultimate pursuit goal is spiritual freedom. He must forget everything and guide people to liberate themselves from the shackles of foreign objects in order to achieve true unlimited and freedom. The focus of Zen practice is "seeing nature with your heart" and "seeing sex as a Buddha", communicating human's ultimate concern with daily life. The former is a "tour" and the latter's liberation is a "certificate." It can be said that Zhuang Zhou is seeking nothing and doing nothing, and Zen is seeking nothing with everything. Life Zen proposes to practice in life, so that the "deep meditation" of Zen is not only religion but also a kind of secular life art. The application of Zen in the real world of human life relieve the various perplexities, troubles, and psychological barriers that exist in modern human life and reflects the peace and tranquility, vitality and joyful mentality of life, which is why people still remain interested in Zen. It also brings the difference between the Chinese Zen and the aesthetic implication of the Japanese Zen. In fact, the Japanese Zen is very biased to the School of Vinaya, and hopes to lead the essence of the Tao through strict discipline, produce the aesthetic pursuit of "Silence", and focus on the impermanence of sadness, and develop the two artistic conception beauties of silence and elegance. Unlike the empty and incomplete beauty of Japanese Zen, life Zen is a kind of optimistic wisdom. It is full of boundless vitality. Its aesthetics concept moves toward harmony in empty space.

\section{BUILD A SYSTEMATIC AND DIVERSIFIED THEME OF 'LIFE ZEN"}

The cultural connotation of Zen Buddhism helps to transform the design theme of Buddhist cultural and creative product from the religious belief of praying for peace to a wider range of cultural themes, develop the product of life Zen theme, and derive a systematic and diversified product system. Simultaneously, considering the practicability of the product, only products that can bear both culture and function can achieve a sustainable commemorative purpose[3].

(1) Meditation series products: In recent years, many Buddhist scenic spots have successively developed meditation as an in-depth experience tourism product, including eating and staying in monasteries, participating in meditation and meditation, listening to the Sanskrit sound, reading the scriptures, tasting vegetarian snacks, watching tea ceremony, and understanding Buddha's teachings. The design of cultural and creative product can be extended to meditation-related items such as Zen cushions, catering equipment, Zen tea utensils, vegetarian foods, and Zen tea packaging.

(2) Daily products: Life Zen points out that spiritual practice exists in all aspects of life, and it implement the practice in life that is every aspect in daily life. It is the value 
and significance of cultural and creative product that products are effectively spread by people. Jumping out of this level of religious practice, choosing appropriate relevant elements for trans-boundary implantation into daily product carriers is an effective method, and it is a design method that stimulates creative sparks [4], like "Bright Moon on Tree" lamp shown in Figure 1. The moon's insipid and tranquil aesthetic image gives the lamps an ethereal and serene beauty of Zen. The cross boundary experience of the lamps and the moon gives people a rich sense of enjoyment.

(3)Zen koan series products: The storytelling provides continuous resources for the subsequent promotion of cultural and creative product, and serialization and branding become relatively simple. The design of the main story or legend of life Zen Buddhism is based on the key elements in the context of the story. It is implicitly expressed in certain representative images and fragments, and finds the appropriate elements and symbols. Instead of the expression of monomer, cultural and creative product expands into a system composed of people, things, and things, and upgrade users' products to cultural and emotional experience.

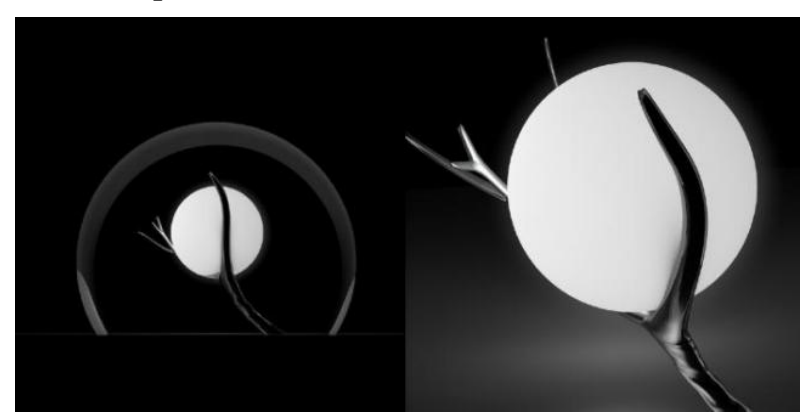

Fig. 2. "Bright Moon on Tree”lamp designed by Tian Bian-han

\section{IMPROVE THE "CONTEXT" OF DESIGN CONNOTATION}

The establishment of the situation requires designers and users to achieve emotional resonance through the design of the middle channel. Using the design symbols on the product, the user associates the meaning of the product with his/her own experience and cognitive experience, and finally completes the process of conveying meaning to the user from the designer.

Nowadays, many of our discussions on the design of the cultural and creative product of Zen still follow the Japanese aesthetics of solitude, and separate a Zen-inspired style from the concept of Zen. The product pursues the beauty of faintness and tranquility and forms a simple and cold product appearance. However, we have overlooked that life Zen is a kind of "promising and living" Zen. It does not evade the present world and uses restrained and harmonious methods to resist external interference. Life Zen promotes the concept of happiness, the pursuit of Zen and returning to spiritual homeland. Zen is the freedom of life from the perspective of belief and spiritual practice. Zen is the coolness of life from the perspective of life practice. Zen is the spirit of thought from the perspective of culture[5]. In the design of Buddhist tourism products, through life Zen, the philosophic thought leads to the design idea with the life wisdom of its optimistic life, and promotes the "state" of the connotation of the design. The "Big-ear Blessed" a set of dishes designed by Rococo's founder, Jia Wei, is a blessing from the folk saying, see Figure 3. The entire design consists of four types, small to large, and expands at every level, which refers to constantly expand the metrics of doing things and continuously improve one's own wisdom. It skillfully uses human cognitive experience to construct a corresponding semantic context: the Buddha's ear is large and the Buddha's heart is broader. The real blessing should be derived from the expansion of mind and self beyond.

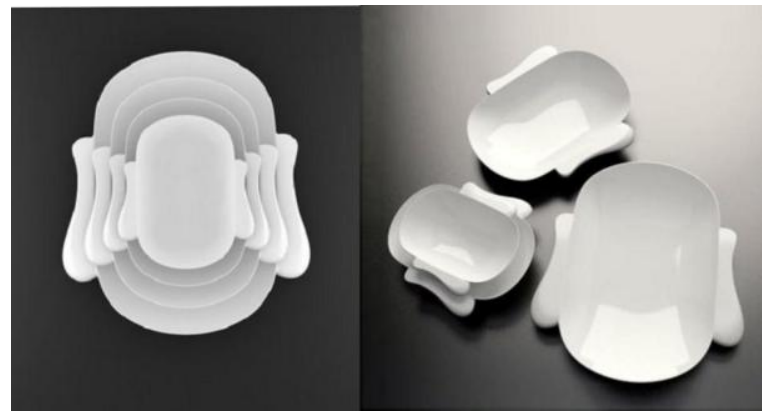

Fig. 3. "Big-ear Blessed” a set of dishes designed by JIA Wei

\section{CROSS-BORDER FUSION OF ZEN ELEMENTS}

The cross-border fusion of elements refers to the use of integration means to recombine the elements of life zen symbols with other seemingly unrelated elements in order to obtain better ideas and new designs. Cross-border integration does not pursue a conceptual or visual correlation between things, but rather harmoniously uses elements in different fields to make design rational.

(1)Form cross-border. Form cross-border is the recombination of morphological elements with similarities and compatibility in different fields, which can convey the culture and spirit, contained in cross-border form elements, and increase the added value of cultural and creative product.

(2)Material cross-border. Different materials produce different tactile and psychological feelings, such as soft and hard, smooth and rough, light and heavy. Material cross-border is to replace the existing material properties with opposite material properties. This innovative nature makes the ordinary things become unknown and unique, showing the incredible creativity. The cultural and creative product of Changsha's back cushion is shown in Figure 4. The back cushion of green hill shape are made of soft fabrics, which break through the most common hard materials such as wood, bamboo, stone, clay and metal in Buddhist cultural and creative product. The crossborder material makes the product extremely innovative.

(3)Platform cross-border. In the era of " Internet+, " cultural and creative product relies on high-tech and Internet platforms to improve its R\&D design value from $3 \mathrm{D}$ to $4 \mathrm{D}$, from static to dynamic, and to achieve the transformation from traditional single cultural products to diversified and high-tech cultural industries. For example, the Zen sound can be played in incense terrace through built-in chips and mobile Bluetooth technology. Or the combination of sachet and AR and 3D can present Zen koan animation story in mobile phone through mobile phone APP scanning two-dimensional code. 


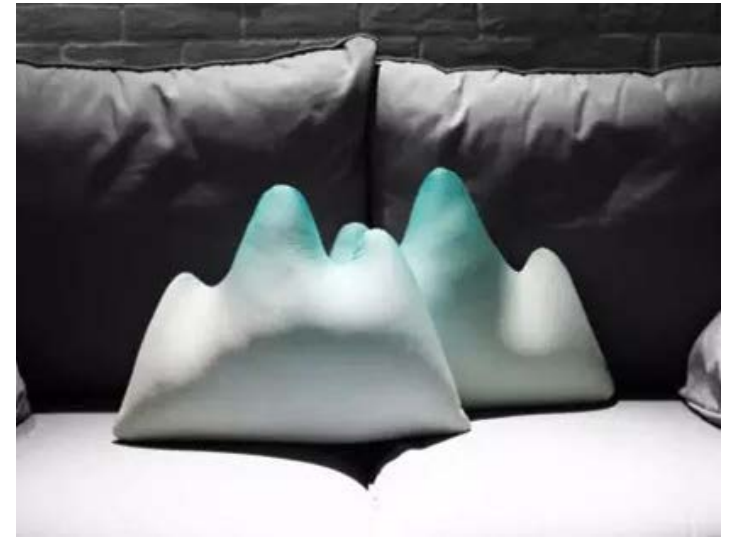

Fig. 4. Back cushion produced

\section{CONCLUSION}

Cultural creative product is a product with market value through creative transformation of cultural resources. It includes three elements, which are "cultural resources", "creative conversion" and "market value". Facing the cultural and creative product market that pursues innovation and connotation value, Zen concept is undoubtedly a new entry point and support point for research and design ideas of cultural and creative product. The life attitude and way of life advocated by the life Zen conforms to the spiritual needs of modern people and helps to transform the design theme of Buddhist cultural and creative product from a religious belief that prays for peace to a broader cultural theme. Through the continuous excavation of the Zen Buddhism culture symbol element, the method of cross boundary design is used to find the fit point, and then the cultural and creative product, with the core of creativity as the core and the living Zen culture as its characteristic, is designed.

\section{REFERENCES}

[1] Hu Huawei. The Sixth Ancestor of Zen and the Chinese of Buddhism[N] Guangming Daily, 2006-10-23 (11).(In Chinese)

[2] Yayoi Yukio. The study of the symbolism of Zen Art [J]. New Fine Arts, 1992 (3): 74-80.

[3] ZHOU Rui. Research of Cultural Creative Product Design for the Relic and Museum Tourism: A Case Study of Chang Dai-chien Cultural Resource [J]. Zhuangshi, 2013(4): 143-144.(In Chinese)

[4] MO Lian. Design Strategy Based on Souvenir and the Related Culture Creative Products[J]. Packaging Engineering, 2016, 37(16):18-21.(In Chinese)

[5] ZHANG Ping. On Interpreting "Zen in the Moment”[A].HUANG Xianian. Life Zen Research[C]. Zhengzhou: The Elephant Press, 2012. 226251.(In Chinese) 